\title{
Characterization of Dissimilar Welding between 304 Stainless Steel and Gray Iron Using Nickel Coated Electrode
}

\author{
Jesús García-Lira1, Enrique Curiel-Reyna1, Yajaira Curiel-Razo', Alberto Lara-Guevara², \\ Ignacio Rojas-Rodríguez ${ }^{3}$
}

\begin{abstract}
${ }^{1}$ Facultad de Estudios Superiores-Cuautitlán, Universidad Nacional Autónoma de México, Cuautitlán-Izcalli, Edo, México ${ }^{2}$ División de Posgrado, Facultad de Informática, Universidad Autónoma de Querétaro, Ave. de las Ciencias S/N, Querétaro, México ${ }^{3}$ División Industrial, Universidad Tecnológica de Querétaro, Querétaro, México Email: *irojasmx@yahoo.com.mx
\end{abstract}

How to cite this paper: García-Lira, J., Curiel-Reyna, E., Curiel-Razo, Y., Lara-Guevara, A. and Rojas-Rodríguez, I. (2021) Characterization of Dissimilar Welding between 304 Stainless Steel and Gray Iron Using Nickel Coated Electrode. Materials Sciences and Applications, 12, 614-621.

https://doi.org/10.4236/msa.2021.1212041

Received: November 15, 2021

Accepted: December 28, 2021

Published: December 31, 2021

Copyright $\odot 2021$ by author(s) and Scientific Research Publishing Inc. This work is licensed under the Creative Commons Attribution International License (CC BY 4.0).

http://creativecommons.org/licenses/by/4.0/

\begin{abstract}
This paper presents the study carried out to study the microstructure and mechanical properties of AISI 304 stainless steel and gray iron, in order to recognize the effect of welding parameters on the joint. The shielded metal arc welding technique was applied with a $3.2 \mathrm{~mm}$ diameter nickel coated electrode under preheating and post heat conditions at $350^{\circ} \mathrm{C}$. Vickers hardness test and metallographic analysis were carried out at the heat affected zone and at the interface to determine the effect on mechanical and metallurgical characteristics. Vickers hardness differences among joint areas were directly related to microstructural changes. There are no significant differences in AISI 304 hardness, but the hardness increased at the heat affected zone and decreased at the filler metal. Grey iron hardness at the heat affected zone was even lower and more slightly superior than grey iron hardness.
\end{abstract}

\section{Keywords}

Dissimilar Metal Welding, Gray Cast Iron, Heat Affected Zone, Preheat and Post Heat Conditions, Stainless Steel AISI 304

\section{Introduction}

Joining two or more metals by welding is a process that has been maintained since its development until today. The earliest examples of welding come from the Bronze Age. During the Iron Age, the Egyptians and the people of the eastern Mediterranean area learned to weld iron pieces. Many tools were found that were made around $1000 \mathrm{BC}[1]$. 
Welding between dissimilar materials is very important as it offers interesting opportunities in modern industrial applications. Consequently, much attention has been paid to the various welding techniques. In the last decade, much importance has been placed on the need to combine different materials, including the welding of dissimilar materials, for specific applications, for example in the automotive and aeronautical industry, most of the structures are built combining materials and very alloys different to obtain better properties and meet the requirements of this industrial sector.

Since its inception, the welding process has evolved to become a useful tool in the metalworking industry, used in the construction and repair of parts. It is a working method whose purpose is to join metals, through reasonably economical techniques, giving the joint suitable properties and compatibility with the base metal (BM). There are welding processes, mainly divided into: fusion, electrical resistance, bond in solid phase or bond in solid-liquid phase [2].

One of the recent challenges in modern industry is to decrease size, designing dissimilar metal welding (DMW). DMW of ductile cast iron (DCI) with austenitic stainless steel (AISI 304) has many applications in different industrial sectors such as oil \& refining and petrochemical industries [3]. DMW has become a critical technology in many areas [4] [5], AISI 304 with low-carbon steel or high-alloy material with low-alloy steel for parts requiring strength and corrosion resistance. There are many applications where welds are made of metals of different compositions.

In DMW, properties of the three metals must be considered, the two that will be joined and the contribution, for example: preheating, control of absorbed heat, thermal expansion, residual stresses, structural changes such as the formation of intermetallic or the presence of high hardness compounds (carbides), among others [6]. DMW has produced a series of technical documents and filler metal selection tables. Many DMW industrial processes do not involve demanding service requirements where a special selection of filler metal would be necessary. DMW does not come with a simple, standardized process that applies to all situations [3].

The joining was carried out using the shielded metal arc welding (SMAW) technique. The DMW process between AISI 304 and DCI, involves mechanical and metallurgical considerations that affect the quality of the joint, such as BM identification and proper FM selection. For this reason, the process design must be done carefully to avoid defects in the weld joint areas or at the heat affected zone (HAZ) [7]. The welding process that is typically used for DMW, is also applied to join similar metals. In all cases, the following must be considered: the composition of the metals to be joined; the bonding or dilution zone of the base metal (DZBM), the filler metal (FM), and the HAZ. DMW like welding of similar metals is done by physically fusing two metals until they form a strong and continuous joint. For the result to be successful, the joint formed must be as strong as the BM in tensile strength, in order to ensure that the joint will be able to withstand stresses to which it is subjected. DMW between DCI and AISI 304 
has many problems due to poor weldability of DCI. DCI has higher carbon content compared to stainless steel, which diffuses on the stainless-steel side during welding and forms hard phases like martensite at the HAZ in addition to forming different carbides in the weld metal zone (WMZ). This leads to developing cracks and affects mechanical properties of welded joints, such as low elongation and high hardness [8].

El-Shennawy and Omar practiced DMW between DCI and stainless steel with different welding processes and different techniques. They found that successful welding can be obtained by using E6013 and E309 electrodes. Hardness decreased and toughness increased at the joint [8]. E.M. Elbana studied the effect of preheating on weldability of cast iron using welding electrode (ENiFe-CI), it is concluded that DCI can be welded with and without preheat and the mechanical properties of weld joint can be improved by applying high preheat temperature $\left(250^{\circ} \mathrm{C}-300^{\circ} \mathrm{C}\right)[9]$.

Elbana et al. studied restoration properties of welded pearlitic cast iron by SMAW process with different welding electrodes applying post welding heat treatment $(\mathrm{PWHT})$ at $677^{\circ} \mathrm{C}$. By welding with ferritic electrode at $300^{\circ} \mathrm{C}$ preheat was the best option to reduce the HAZ width. PWHT reduced maximum hardness values of weld metal and HAZ. By using high Ni content electrodes, carbides formation was reduced [10] [11]. SMAW process is considered the most common welding process in construction, maintenance and repairs.

Stainless steels of AISI 300 series are considered the most suitable alloys for service under oxidation conditions. However, it must be considered that they are materials that have different types of structures and phases which determine the physical and chemical properties in service.

Microstructural changes at the HAZ of stainless steels depend on the BM, the reached maximum temperature and heating and cooling rates. Schematizing HAZ in different regions, the supercritical zone is where grain growth occurs, which is why it is considered the most fragile HAZ. Generally, the resulting microstructure at the $\mathrm{HAZ}$ is different from that of the $\mathrm{BM}$, but very similar to that of the weld metal in stainless steels. The HAZ occurs in a narrow region difficult to distinguish. The HAZ formation can be explained in terms of thermal cycles and temperatures to which it is exposed [11].

This study focuses on determining the appropriate conditions to weld joints between DCI and AISI 304 using the SMAW process, in order to recognize the effect of FM different parameters on the joint properties and microstructure.

\section{Materials and Methods}

The methodology applied in this work consisted of, first selecting the samples (Stainless steel and gray cast iron); sectioning the samples; preheating the samples to a temperature of $350^{\circ} \mathrm{C}$; welding of samples; cutting to obtain samples; hardness tests and Metallographic analysis.

Three samples of GCI and AISI 304 were welded by SMAW under preheating and post heat conditions at $350^{\circ} \mathrm{C}$. The chemical composition of AISI 304 and 
gray iron is shown in Table 1.

Sample dimensions were $160 \mathrm{~mm} \times 50 \mathrm{~mm} \times 6 \mathrm{~mm}$. Each specimen was obtained from one AISI 304 plate welded to one DCI (pearlitic) plate. Figure 1 illustrates the sample cross section.

\subsection{Experimental and Welding Procedure}

The welding technique used in this study was SMAW, also known as coated electrode welding. It is a manual process that uses a consumable electrode or metal rod in the core, covered with flux. It can be used to weld many types of metals, including carbon steel, stainless steel, and DCI.

Samples were preheated at $350^{\circ} \mathrm{C}$ before the SMAW technique. The FM was a $3.2 \mathrm{~mm}$ diameter nickel coated electrode (E-NiCI). The current intensity was 80 A using a 300 A Hobart welding machine with motor DC series PI. Welded plates were post heated at $350^{\circ} \mathrm{C}$ for 45 minutes, and subsequently, cooled in calm air.

Preheating the DCI BM improves ductility, decreases hardness, and reduces the likelihood of fissures or cracks during welding.

\subsection{Hardness Test}

Vickers hardness measurements were carried out on the cross section of welded specimens. A Vickers Model Amsler hardness tester was used applying a $2 \mathrm{Kgf}$ load. 50 Vickers hardness readings were inspected between $127 \mu \mathrm{m}$ indentation. Inspection was transverse, through the MB, HAZ and FM areas, which average results are shown in Table 2.

\section{Results and Discussion}

Welded samples were visually examined to detect possible macroscopic defects. Hardness tests and metallographic analysis were carried out to determine mechanical and metallurgical characteristics.

Figure 2 shows hardness variations of sample cross sections, where hardness differences among AISI 304, HAS, FM and DCI can be observed.

Table 1. Chemical composition of AISI 304 and gray iron.

\begin{tabular}{cccccccc}
\hline Material & $\% \mathrm{C}$ & $\% \mathrm{Cr}$ & $\% \mathrm{Ni}$ & $\% \mathrm{Mn}$ & $\% \mathrm{Si}$ & $\% \mathrm{~S}$ & $\% \mathrm{P}$ \\
\hline AISI304 & 0.081 & 18.20 & 8.40 & 1.86 & 0.86 & 0.03 & 0.035 \\
Gray Iron & 2.97 & --- & --- & 0.88 & 1.86 & 0.20 & 0.28 \\
\hline
\end{tabular}

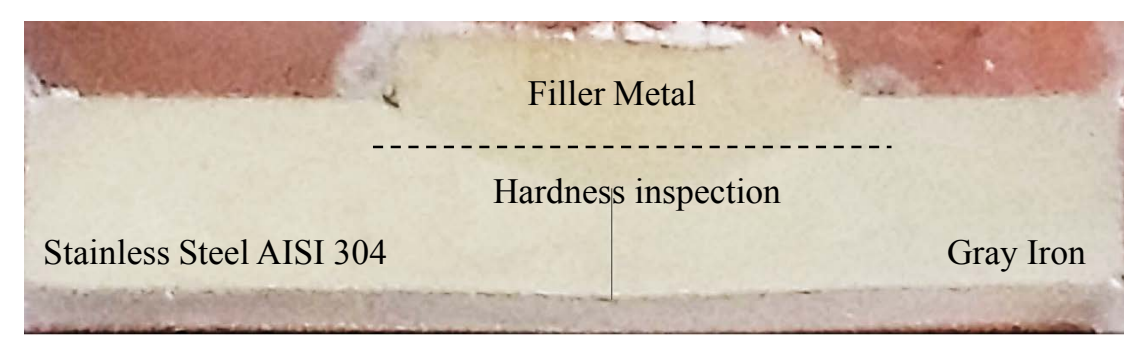

Figure 1. Cross section of one welded sample in polished condition. 
Table 2. Average Vickers hardness of AISI 304 and DCI joints.

\begin{tabular}{ccccc}
\hline Sample & AISI 304 & HAZ & FM & DCI \\
\hline 1 & 289 & 410 & 368 & 296 \\
2 & 293 & 415 & 340 & 334 \\
3 & 288 & 415 & 354 & 312 \\
Average & 290 & 413 & 354 & 314 \\
\hline
\end{tabular}

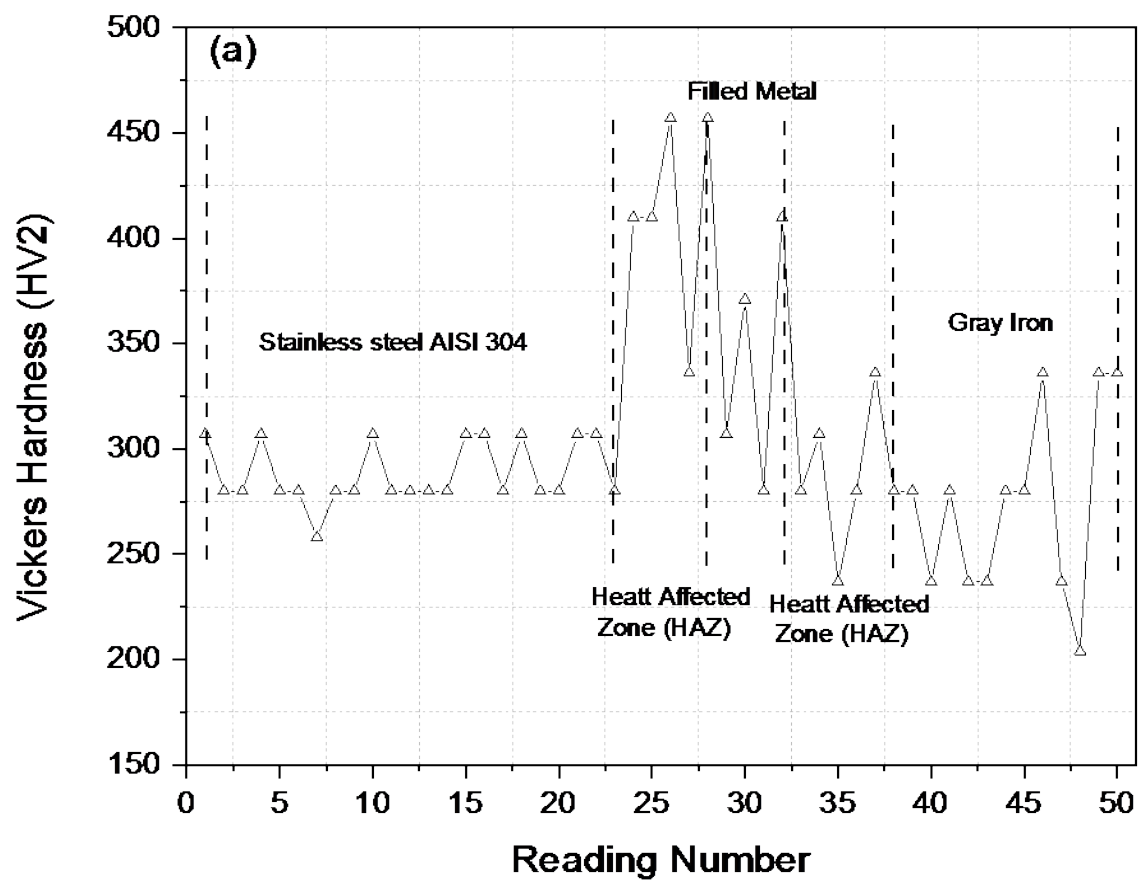

Figure 2. Hardness variations among AISI 304, HAS, FM and DCI areas.

\subsection{Metallographic Study}

Samples were metallographically prepared by roughing with 240, 320, 400, 600 and 1000 Fandeli-USA sandpaper. Then, a preliminary polishing with $10 \mu \mathrm{m}$ alumina, and finally, an electrochemical polishing with oxalic acid at $6 \mathrm{~V} \mathrm{DC}$.

Samples were analyzed with an Olympus light microscope, at 50×, 400×, 600× and $800 \times$ magnifications, mainly on the HAZ and the ligament.

Figure 3(a) shows differences among FM, BM and the fusion line. Around the fusion line, grain growth was observed both at FM and BM (austenite) areas. There was an increasing grain size at the HAZ.

Figure 3(b) illustrates the presence of an intergranular intermetallic compound. A grain growth appeared at the HAZ of the AISI 304 BM area, which was caused by an elevated temperature during the welding process.

In Figure $3(\mathrm{c})$ the precipitation of intermetallic compounds is shown clearly. These precipitates resulted from a fine morphology of the AISI 304 BM austenite crystals at the HAZ. Perlite grains were probably formed from the FM.

In Figure 3(d) the presence of a precipitate with a very fine morphology can 


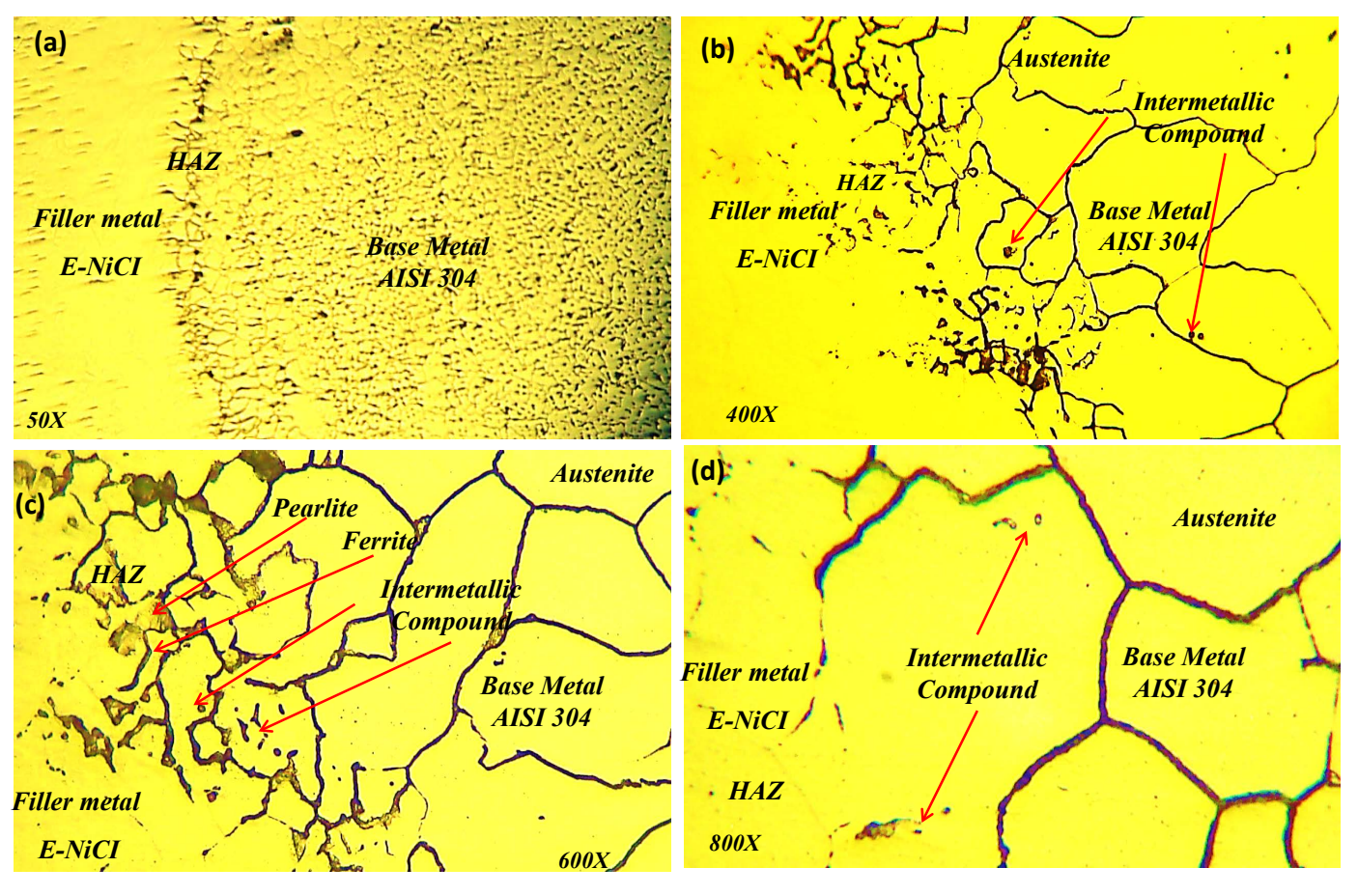

Figure 3. Metallographic structure of FM, HAZ and BM AISI 304 areas. (a) 50×; (b) 400×; (c) 600×; (d) $300 \times$.

be observed. It can be assumed that it is a $\mathrm{Ni}$ compound as a result of the FM and the AISI $304 \mathrm{BM}$, due to the welding process with preheating and post heating.

Curiel-Reyna et al. found that in the welding of Hadfield steel, the postcooling rate of the heat treatment process affected mechanical properties as a consequence of the metallurgical structure changes at the HAZ and welded area. Metallurgical structure changes resulted from discontinuities at grain boundaries due to internal stresses after the post cooling process. This effect at the HAZ is similar to the results of this study by the welding process of AISI 304 and DCI.

\subsection{Hardness}

Figure 4 shows the hardness distribution of welded samples at the AISI 304 BM, FM and DCI areas. According to average hardness results shown in Table 1, AISI 304 Vickers hardness increased at the HAZ. This increase was due to the grain growth shown in Figure 3(b). FM Vickers hardness decreased slightly, and finally; DCI Vickers hardness decreased.

\subsection{Microstructure}

In Figure 3(a) an austenitic structure is observed as well as grain growth in some areas. In Figure 3(b) and Figure 3(c), the structure is shown in detail with pearlite and ferrite formations in the transition zone (melting line), with a predominantly austenitic structure both in the BM and in the FM. The grain growth was a result of the melting process during electric arc welding. 


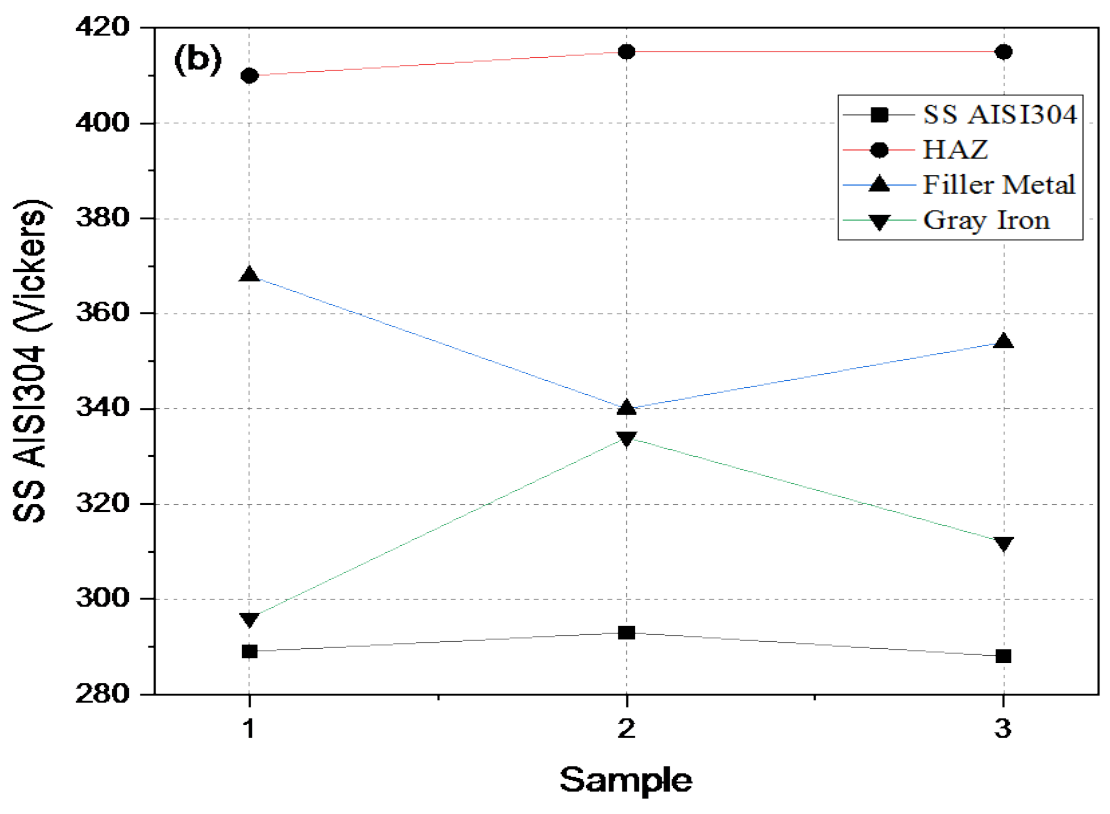

Figure 4. Vickers hardness variation of sample 1 at the junction cross section.

\section{Conclusions}

According to the results, the difference in hardness between AISI304 stainless steel and gray iron is directly related to the changes in the metallurgical microstructure. In the case of AISI 304, there are no significant differences in the hardness, but the hardness increased at the HAZ, and tended to decrease at the FM. GCI hardness at the HAZ was even lower, slightly higher than GCI.

The metallographic microstructure analysis as a result of the welding process, was allowed to determine microstructural changes and their effect on hardness results. The grain size increased at the HAZ due to temperature effect during the welding process. Thus, it can be concluded that:

1) AISI 304 and DCI can be welded with preheating at $350^{\circ} \mathrm{C}$.

2) The nickel coated electrode by SMAW promoted the formation of intermetallic compounds without significant hardness.

3) DMW of AISI 304 and DCI with nickel coated electrode by SMAW raised microhardness values more than $450 \mathrm{HV}$. This can be useful for DCI special applications.

4) Considering the hardness, the metal resistance at the HAZ is higher than the FM.

\section{Conflicts of Interest}

The authors declare no conflicts of interest regarding the publication of this paper.

\section{References}

[1] Cary, H.B. (1998) The History of Welding. In Cary, H.B., Ed., Modern Welding Technology, Prentice-Hall, Hoboken, New Jersey. 
[2] Sehsah, A.M., Ghanem, H., Abdel-Aleem, A. and El-Shennawy, M. (2021) Dissimilar Welding of Ductile Cast Iron to 304 Stainless Steel. International Journal of Mechanical Engineering, 10, 35-48.

[3] Davis, J.R. (1994) ASM Specialty Handbook: Stainless Steel. ASM International, Almere, Netherlands.

[4] Praveen, P. and Yarlagadda, P.K.D.V. (2005) Meeting Challenges in Welding of Aluminum Alloys through Pulse Gas Metal Arc Welding. Journal of Materials Processing Technology, 164-165, 1106-1112. https://doi.org/10.1016/j.jmatprotec.2005.02.224

[5] Aizawa, T., Kashani, M. and Okagawa, K. (2007) Application of Magnetic Pulse Welding for Aluminum Alloys and SPCC Steel Sheet Joints. Welding Journal, 86, 119-124.

[6] Naffakh, H., Shamanian, M. and Ashrafizadeha, F. (2009) Investigation on AISI 304 Austenitic Stainless Steel to AISI 4140 Low Alloy Steel Dissimilar Joints by Gas Tungsten Arc, Electron Beam and Friction Welding. Journal of Materials Processing Technology, 209, 3628-3639. https://doi.org/10.1016/j.jmatprotec.2008.08.019

[7] Mills, K., et al. (1983) Welding Book. Metals handbook, 6, 2045-2050.

[8] El-Shennawy, M. and Omar, A.A. (2010) Similar and Dissimilar Welding of Ductile Cast Iron. In: Hinduja S. and Li, L., Eds., Proceedings of the 36th International MATADOR Conference, Springer, London.

https://doi.org/10.1007/978-1-84996-432-6_68

[9] El-Banna, E.M. (1999) Effect of Preheat on Welding of Ductile Cast Iron. Materials Letters, 41, 20-26. https://doi.org/10.1016/S0167-577X(99)00098-1

[10] El-Bannaa, E.M., Nagedaa, M.S. and Abo El-Saadatb, M.M. (2000) Study of Restoration by Welding of Pearlitic Ductile Cast Iron, Materials Letters, 42, 311-320.

[11] Curiel-Reyna, E., Rojas-Rodriguez, I., Teran, J., Del Real, A., Lara Guevara, A. and Rodriguez-García, M.E. (2014) Postcooling Treatment Impact on Mechanical Properties of Welded Hadfield Steel Pieces. Journal of Emerging Trends in Engineering and Applied Sciences (JETEAS), 5, 105-110. https://doi.org/10.1016/S0167-577X(99)00204-9 